\title{
BMJ Open Associations between physical behaviour patterns and levels of depressive symptoms, anxiety and well-being in middle-aged adults: a cross-sectional study using isotemporal substitution models
}

\author{
Christina B Dillon, ${ }^{1}$ Elaine McMahon, ${ }^{2}$ Grace O'Regan, ${ }^{2}$ Ivan J Perry ${ }^{1}$
}

To cite: Dillon CB, McMahon E, O'Regan G, et al. Associations between physical behaviour patterns and levels of depressive symptoms, anxiety and well-being in middleaged adults: a cross-sectional study using isotemporal substitution models. BMJ Open 2018;8:e018978. doi:10.1136/ bmjopen-2017-018978

- Prepublication history for this paper is available online. To view these files, please visit the journal online (http://dx.doi. org/10.1136/bmjopen-2017018978).

Received 8 August 2017 Revised 9 November 2017 Accepted 10 November 2017

Check for updates

${ }^{1}$ Department of Epidemiology and Public Health, HRB Centre for Diet and Health Research, University College Cork, Cork, Ireland

${ }^{2}$ National Suicide Research Foundation, University College Cork, Cork, Ireland

Correspondence to Dr Christina B Dillon; c.dillon@ucc.ie

\section{ABSTRACT}

Objective To examine the compositional effects of physical behaviour on mental health.

Design Cross-sectional study.

Setting A population-representative random sample (Mitchelstown cohort) was recruited from a large primary care centre in Mitchelstown, County Cork, Ireland.

Participants In total 3807 potential participants were selected from the practice list. Following exclusion of duplicates, deaths and ineligibles, 3043 were invited to participate and of these, 2047 (49.2\% men) completed the questionnaire and physical examination components of the baseline assessment during the study period (April 2010 and May 2011). Accelerometers were introduced into the study in January 2011. Of the 745 participants seen between January and May of 2011, $475(44.6 \%$ men) subjects (response rate $64 \%)$ agreed to participate and of these 397 ( $46.1 \%$ men) had valid accelerometer data.

\section{Primary and secondary outcome}

measures Participants wore the wrist GENEActiv accelerometer for 7 consecutive days. Data were summarised into $60 \mathrm{~s}$ epochs and activity categorised as sedentary behaviour, light or moderate-to-vigorous physical activity (MVPA). Levels of depressive and anxiety symptoms were assessed using the Centre for Epidemiologic Studies Depression scale and the Hospital Anxiety and Depression Scale. Well-being was assessed using the WHO-5 well-being scale.

Results In adjusted isotemporal models, a $30 \mathrm{~min}$ increase in light activity per day was associated with a significant decrease in levels of anxiety symptoms $(\mathrm{B}=-0.34 ; 95 \% \mathrm{Cl}-0.64$ to -0.04$)$ and a significant increase in levels of well-being $(B=0.58 ; 95 \% \mathrm{Cl}$ 0.05 to 1.11 ). No statistically significant associations were observed between any physical behaviour and depressive symptoms or when sedentary behaviour was substituted with MVPA $(P>0.05)$.

Conclusion Although based on a cross-sectional study, the findings suggest that substituting light activity for sedentary behaviour may have positive associations with symptoms of anxiety and reported well-being among middle-aged adults.

\section{Strengths and limitations of this study}

- The use of a valid and reliable activity monitor which is capable of assessing time spent in sedentary, light, moderate and vigorous activity categories represents a significant strength of this study.

- This study had a high participation rate and large sample size for an accelerometer-based study.

- This study used cross-sectional analysis thus reverse causation is a potential limitation.

- Physical activity data were collected over a 1-week period which may not reflect habitual physical activity levels over a longer time period, that is, month or year.

- Generalisability of these findings may also be limited; the Mitchelstown cohort was a random sample of middle-aged adults, 50-69 years of age, in an area which was representative of both urban and rural population in Ireland.

\section{INTRODUCTION}

Mental disorders such as depression and anxiety are major public health concerns. According to the $\mathrm{WHO}$, the number of people experiencing depression and/or anxiety increased by approximately $50 \%$ between 1990 and 2013, from 416 to 615 million. ${ }^{1}$ It is estimated that mental disorders account for $30 \%$ of the global non-fatal disease burden. ${ }^{1}$ The burden of mental disorders extends far beyond the condition itself, affecting quality of life, cognitive function, psychosocial health, and all-cause and suicide mortality risk. ${ }^{2}$ Many epidemiological studies have documented associations between physical behaviour and mental health. ${ }^{3-12}$ Being physically active is a major contributor to both physical and mental health. ${ }^{7-12}$ A comprehensive body of highquality evidence has found physical activity to reduce depression and anxiety in non-clinical populations. ${ }^{13}$ 
Although there is a growing body of literature examining the beneficial effects of light activity and moderate-to-vigorous activity (MVPA), the impact of substituting sedentary behaviour with light activity or MVPA on mental health outcomes is less known. ${ }^{14}$ Furthermore, the majority of previous research has used subjective measures of physical behaviour which are prone to measurement error and bias. ${ }^{15}$ Limitations of subjective measures include over-reporting of physical activity levels, often due to social desirability bias ${ }^{16-18}$ and failure of instruments to account for the least intense or shortest activities. ${ }^{19-22}$ Questionnaires lack emphasis on light-intensity activities and often do not take into account the fragmentation of physical behaviour episodes. ${ }^{23}{ }^{24}$ Accelerometers overcome these issues as they allow for the objective measurement of physical behaviour and thus avoid reporting errors created by translation, misinterpretation and social desirability bias. ${ }^{25}$

The daily time we are able to move and participate in physical behaviour is limited. We can only undertake one type of behaviour at any time thus a specific behaviour undertaken at a certain time will have heterogeneous effects on an outcome depending on the other activities being displaced. The isotemporal substitution model allows for the study of these time displacement effects, substituting one physical behaviour for another. Isotemporal substitution analysis concurrently models the specific physical behaviour being performed and the specific behaviour being displaced in an equal time-exchange manner (ie, $30 \mathrm{~min}$ ). Thus, the isotemporal model controls for the confounding effect of other behaviours and the effect of time substitution and reduces heterogeneity in the associations. The isotemporal substitution model has been used to investigate the statistical substitution of sedentary behaviour with other physical activity intensities on various health outcomes. ${ }^{14} 15$ 26-29 However, only two studies have examined associations with mental health outcomes. ${ }^{14} 26$ Mekary et $a l^{14}$ found a significant improvement in depression risk when 60 min per day of television viewing was replaced with an equal amount of brisk walking. Loprinzi $e t a l^{26}$ reported significantly lower odds of suffering depression with a $60 \mathrm{~min}$ increase in light activity.

Few studies have examined the compositional, interdependent effects of physical behaviour on mental health outcomes. Understanding the effects of substituting different physical behaviours on health outcomes is important for the development of physical behaviour guidelines, health promotion programmes and intervention studies. The aim of this study was to examine cross-sectional associations between physical behaviour patterns and indicators of mental health and well-being using single and isotemporal substitution analyses.

\section{METHODS}

\section{Subjects}

A population-representative random sample (Mitchelstown Cohort) was recruited from a large primary care centre in Mitchelstown, County Cork, Ireland. ${ }^{30}$
Participants were randomly selected from all registered attending patients in the 50-69year age group. In total 3807 potential participants were selected from the practice list. Following exclusion of duplicates, deaths and ineligibles, 3043 were invited to participate in the study and of these, 2047 (49.2\% men) completed the questionnaire and physical examination components of the baseline assessment (response rate 67\%) during the study period (April 2010 and May 2011). Accelerometers were introduced into the study in January 2011. Of the 745 participants seen between January and May of 2011, 475 (44.6\% men; mean aged $59.6 \pm 5.5$ years) subjects agreed to participate (response rate 64\%) and of these, 397 (46.1\% men; mean 59.6 \pm 5.5 years) had valid accelerometer data (at least 10 hours of wear time activity during daytime hours on all days). The subsample of the Mitchelstown Cohort, for whom accelerometer data was collected, differed by gender in that women were more likely to agree to wear the accelerometer. However, there were no statistically significant differences in age, education or body mass index (BMI) between those included and excluded in the final analysis in both men and women.

\section{Accelerometer protocol}

Objective physical behaviour levels were assessed using a triaxial, GENEActiv accelerometer. The accelerometer (ActivInsights Ltd, Kimbolton, Cambridgeshire, UK) comprised a triaxial accelerometer with a dynamic range of $\pm 8 \mathrm{~g}\left(1 \mathrm{~g}=9.81 \mathrm{~m} / \mathrm{s}^{2}\right)$, where $\mathrm{g}$ represents gravitational unit, and was attached to the participants' preferred wrist with a strap. The technical reliability and validity of this accelerometer and detailed methods of the accelerometer protocol have been reported elsewhere. ${ }^{31} 32$ For the current study, acceleration was sampled at $100 \mathrm{~Hz}$ and the accelerometer worn for 7 consecutive days. Following return of the accelerometer to the co-ordination centre, data were extracted using GENEActiv software and then collapsed into a specific time interval (epoch), for example, $60 \mathrm{~s}$ epoch. Each time interval, from the daytime wear-time (6-12 am) periods, was categorised based on validated cut-off points for dominant and non-dominant wrist wear. ${ }^{32}$ Wear and non-wear time was identified by the procedure outlined by Van Hees et $a l .{ }^{33}$ In the Mitchelstown study, physical activity was also measured subjectively using the International Physical Activity Questionnaire-Short Form (IPAQ-SF). However, validation analysis found low levels of agreement between the two measures (Cohen's Kappa $(\mathrm{K}=0.011))$.

\section{Outcomes measures}

The Centre for Epidemiologic Studies Depression (CESD) 20-item symptom scale was used to assess symptoms of depression. ${ }^{34}$ Scores range from 0 to 60 , with higher scores indicative of higher levels of depressive symptoms; $<15$ indicate no symptoms, 15-21 and $>21$ signify mildto-moderate and possibility of major depression, respectively. CESD scores with $<16$ questions answered were excluded from the analysis. 
Anxiety was assessed using the anxiety section (seven items) of the Hospital Anxiety and Depression Scale (HADS).$^{35}$ A score 0-7 signifies no anxiety, 8-10 mild anxiety, 11-15 moderate anxiety and $>15$ indicates severe anxiety. Anxiety scores ranged from 0 to 21 and any case with more than one question unanswered were excluded from the analysis. For the purposes of this analysis, cut-offs of mild-to-moderate symptoms of depression and moderate symptoms of anxiety were used for descriptive analysis.

Well-being was assessed using the WHO-5 well-being index. ${ }^{36}$ Each of the five items is rated on a 6-point Likert scale from 0 (not present) to 5 (constantly present). The raw score ranged between 0 and 25 and was used in regression and descriptive analyses. A dichotomous variable was created for additional descriptive analysis; a score of $<13$ indicated poor well-being and $\geq 13$ indicated good well-being. Participants were excluded from analysis if more than two questions were unanswered.

\section{Potential covariates}

Demographic, behavioural and comorbidity characteristics were measured by a combination of self-reported (gender, smoking status, alcohol intake, education, season and marital status) and interviewer assessed (age, height and weight) measures. BMI was calculated as (weight $(\mathrm{kg}) /(\text { height }(\mathrm{m}))^{2}$ ).

\section{Statistical analysis}

Descriptive analyses were used to examine sample differences by study covariates and patterns of physical behaviour across intensity categories by depression, anxiety and well-being measures. Isotemporal substitution was used to examine associations between statistically replacing $30 \mathrm{~min}$ per day of sedentary behaviour with equal amounts of light activity and MVPA on levels of depressive and anxiety symptoms and well-being. Isotemporal analyses examined each activity intensity while adjusting for time in other physical behaviours and total time. More specifically, the coefficient from an isotemporal model represents the estimated effects of substituting a specific activity intensity for the category dropped while holding total wear time and other activities constant. ${ }^{38}$ Therefore, if we assess the effect of replacing sedentary behaviour with MVPA we include light activity, MVPA and total wear time in the model whereas a model examining the effects of replacing MVPA with sedentary behaviour would include sedentary behaviour, light activity and total time. The isotemporal model is a linear regression model. Thus the coefficients represent the effects for every $30 \mathrm{~min}$ increase substitution on a one-unit increase in symptoms of depression, anxiety or well-being. These models are described in greater detail elsewhere. ${ }^{14}$ Data are reported as median and 25th and 75th percentiles unless otherwise stated. Analyses were adjusted for gender, age, season, marital status, smoking status, alcohol consumption, BMI status and education. All statistical analyses were conducted using Stata (V.12, Stata Corp, College Station, Texas, USA).

\section{RESULTS \\ Descriptive characteristics of study sample}

Three hundred and ninety-six participants had valid accelerometer data (men: $46.1 \%$; mean age 59.6 55.5 years). The prevalence of mild-to-major levels of depressive and anxiety symptoms that indicate risk of clinical diagnoses were $18.2 \%$ and $9.5 \%$, respectively, while $35 \%$ of the study population reported poor well-being. Median levels of depressive, anxiety and well-being symptoms are presented by study sample demographic characteristics in table 1.

Statistically significant differences in symptoms of anxiety were observed across gender and age $(\mathrm{P}<0.02)$. No statistically significant associations were observed with symptoms of depression $(\mathrm{P}>0.05)$ or reported wellbeing, with the exception of age $(\mathrm{P}<0.001)$. Furthermore, no statistically significant differences were observed in symptoms of depression, anxiety or well-being and BMI status $(\mathrm{P}>0.05)$. Physical behaviour characteristics by categories of depressive, anxiety and well-being indicators are presented in table 2. Statistically significant differences were observed for all physical behaviour intensities with anxiety and well-being categories $(\mathrm{P}<0.05)$, with the exception of MVPA for anxiety categories $(\mathrm{P}=0.13)$. Overall, those with anxiety symptoms and those who reported poor well-being had higher sedentary behaviour levels and lower physical activity levels than their counterparts. No significant differences were observed between physical behaviour and depression.

Associations between physical behaviour intensity, depressive and anxiety symptoms and well-being

The results of isotemporal substitution regression analyses models are presented in tables $3-5$. No statistically significant associations were observed for crude analyses of associations between physical behaviour and levels of depressive symptoms, anxiety and well-being for any physical behaviour model $(\mathrm{P}>0.05)$, with the exception for light activity and well-being. A significant increase in levels of well-being symptoms was observed when $30 \mathrm{~min}$ of sedentary behaviour was substituted with $30 \mathrm{~min}$ of light activity ( $\mathrm{B}=0.48 ; 95 \% \mathrm{CI} 0.02$ to 0.94$)$.

A significant association between light activity and levels of anxiety symptoms and well-being were found in adjusted analyses. In adjusted models, a $30 \mathrm{~min}$ increase in light activity per day was associated with a significant decrease in levels of anxiety symptoms $(B=-0.34 ; 95 \%$ CI -0.64 to -0.04$)$ and a significant increase in well-being $(\mathrm{B}=0.58 ; 95 \% \mathrm{CI} 0.05$ to 1.11$)$. No statistically significant associations were observed between any physical behaviour and depressive symptoms, nor when sedentary behaviour was substituted for MVPA in terms of symptoms of anxiety or levels of well-being $(\mathrm{P}>0.05)$. 
Table 1 Levels of depressive, anxiety and well-being symptoms by demographic characteristics

\begin{tabular}{|c|c|c|c|c|c|c|}
\hline & $\begin{array}{l}\text { Depression }{ }^{\star 1} \\
\text { (CESD } \\
\text { questionnaire) }\end{array}$ & $P$ value & $\begin{array}{l}\text { Anxiety }^{\star 2} \\
\text { (HADS- } \\
\text { modified) }\end{array}$ & $P$ value & $\begin{array}{l}\text { Well-being }{ }^{\star 3} \\
\text { (WHO-5 well- } \\
\text { being index) }\end{array}$ & $P$ value \\
\hline \multicolumn{7}{|l|}{ Sex } \\
\hline $\operatorname{Man}(n=182 ; 46.1 \%)$ & $8(3,13)$ & & $4(3,6)$ & & $18(13,20)$ & \\
\hline Woman $(n=214 ; 53.9 \%)$ & $9(4,13)$ & 0.24 & $5(4,7)$ & 0.0009 & $18(13,20)$ & 0.54 \\
\hline \multicolumn{7}{|l|}{ Age (years) } \\
\hline $50-59(n=212 ; 54.4 \%)$ & $9(4,13)$ & & $5(4,7)$ & & $17(12,20)$ & \\
\hline $60-69(n=178 ; 45.6 \%)$ & $8(3,13)$ & 0.44 & $5(3,6)$ & 0.01 & $19(15,21)$ & 0.0003 \\
\hline \multicolumn{7}{|l|}{ Education } \\
\hline Primary (n=101; 26.7\%) & $8(4,14)$ & & $5(3,7)$ & & $18(13,20)$ & \\
\hline Secondary/Tertiary $(n=278 ; 73.3 \%)$ & $9(4,13)$ & 0.77 & $5(3,7)$ & 0.82 & $18(14,20)$ & 0.64 \\
\hline \multicolumn{7}{|l|}{ Season } \\
\hline Winter/Spring $(n=278 ; 70.2 \%)$ & $8(4,13)$ & & $5(3,7)$ & & $18(13,20)$ & \\
\hline Summer ( $n=118 ; 29.8 \%)$ & $9(4,13)$ & 0.58 & $5(3,6)$ & 0.34 & $18(14,20)$ & 0.44 \\
\hline \multicolumn{7}{|l|}{ Alcohol intake } \\
\hline Non-moderate drinker $(n=86 ; 22.7 \%)$ & $7(4,12)$ & & $5(3,7)$ & & $18(15,20)$ & \\
\hline Moderate drinker $(n=188 ; 68.6 \%)$ & $9(4,13)$ & 0.89 & $5(4,7)$ & 0.87 & $18(13,20)$ & 0.37 \\
\hline \multicolumn{7}{|l|}{ Smoking status } \\
\hline Never $(n=203 ; 52.6 \%)$ & $7(3,12)$ & & $5(3,6)$ & & $18(14,20)$ & \\
\hline Former $(n=126 ; 32.6 \%)$ & $8(4,13)$ & & $5(3,7)$ & & $18(14,20)$ & \\
\hline Current smoker $(n=57 ; 14.8 \%)$ & $11(6,16)$ & 0.09 & $5(3,7)$ & 0.52 & $16(11,20)$ & 0.24 \\
\hline \multicolumn{7}{|l|}{ Marital status } \\
\hline Not married $(n=89 ; 22.7 \%)$ & $10(4,15)$ & & $5(3,6)$ & & $17(12,20)$ & \\
\hline Married (n=304; 77.3\%) & $8(4,13)$ & 0.17 & $5(3,7)$ & 0.32 & $18(14,20)$ & 0.09 \\
\hline \multicolumn{7}{|l|}{ BMI status } \\
\hline Normal weight $(\mathrm{n}=79 ; 20.0 \%)$ & $2(1,3)$ & & $1(1,2)$ & & $3(2,3)$ & \\
\hline Overweight $(n=189 ; 47.7 \%)$ & $2(1,3)$ & & $1(1,2)$ & & $3(2,3)$ & \\
\hline Obese $(n=128 ; 32.3 \%)$ & $2(1,3)$ & 0.43 & $1(1,2)$ & 0.93 & $3(2,3)$ & 0.29 \\
\hline
\end{tabular}

Vales are presented as median (25th, 75th percentiles).

${ }^{*}$ Continuous score ${ }^{1} 0-60$ range ${ }^{2} 0-21$ range ${ }^{3} 0-25$ range.

BMI, body mass index; CESD, Centre for Epidemiologic Studies Depression; HADS, Hospital Anxiety and Depression Scale.

\section{DISCUSSION}

In this study, we have cross-sectionally examined the compositional effects of physical behaviour on mental health among a sample of middle-aged adults. Isotemporal models identified a significant decrease in levels of anxiety symptoms and a significant increase in well-being when 30 min of sedentary behaviour was substituted with light activity. No significant associations were observed when substituting sedentary behaviour with MVPA or between any physical behaviour and depressive symptoms.

To our knowledge this is the first study to examine the compositional effects of physical activity on symptoms of anxiety and reported well-being. Furthermore, limited research exists examining the association between the compositional effects of physical behaviour on mental health outcomes. ${ }^{146}$ Two previous studies have examined this relationship using isotemporal analysis, both have concentrated on depressive symptoms. Loprinzi et $a l^{26}$ reported that a $60 \mathrm{~min}$ increase in light activity was associated with significantly lower odds of suffering from depression, while Mekary et $a l^{14}$ reported a significant reduction in depression risk when $60 \mathrm{~min} /$ day of television viewing was replaced with an equal amount of brisk walking. The current study findings are in contrast to these as in this study we observed no significant association between any physical behaviour and depressive symptoms. These contrasting findings may be related to the use of different measures of physical behaviour in each study. Mekary et $\mathrm{al}^{14}$ captured physical behaviour levels subjectively using self-reported surveys which are prone to measurement error and bias. Mekary and colleagues noted that intensity of activity appears to matter in terms of protecting against depression, brisk walking but not walking at an average pace was associated with lower risk of depression when substituted for $60 \mathrm{~min} /$ day of television watching. ${ }^{16}$ Thus, the low frequency of MVPA in this sample of 
Table 3 Depressive symptoms: isotemporal substitution analysis of $30 \mathrm{~min} /$ day replacement of physical behaviours

\begin{tabular}{|c|c|c|}
\hline & Crude & Adjusted \\
\hline & Isotemporal & Isotemporal \\
\hline & B (95\% Cl) & B $(95 \%$ Cl) \\
\hline $\begin{array}{l}\text { Sedentary } \\
\text { activity }\end{array}$ & Replaced & Replaced \\
\hline Light activity & $-0.55(-1.20$ to 0.10$)$ & $-0.63(-1.51$ to 0.26$)$ \\
\hline MVPA & $0.09(-0.49$ to 0.68$)$ & $-0.25(-1.09$ to 0.59$)$ \\
\hline
\end{tabular}

Models are adjusted for age, gender, season, marital status, smoking status, alcohol consumption, BMI status and education. No values are significant to $P<0.05$.

$\mathrm{BMI}$, body mass index; MVPA, moderate-to-vigorous physical activity.

middle-aged adults may lead to non-significant findings in terms of associations between MVPA and depressive symptoms. Loprinzi et $a l^{26}$ used objective measures of physical behaviour, the ActiGraph. This accelerometer measures acceleration of the body at the hip while the GENEActiv accelerometer measures acceleration at the wrist. The movement or acceleration of the body differ significantly at these two positions and thus measurements may be incomparable. In addition to different measurements positions, both devices use different thresholds to categories physical behaviour intensities. Thus, differences in the measurement and categorisation of physical behaviour affect the comparability of the current findings to previous research. Unusually, no significant association was observed in this study between physical behaviour substitution and depressive symptoms, despite significant associations being observed with anxiety and well-being. First, as previously stated, a large body of evidence exists supporting an association between physical activity and depression. However, limited research exists examining the displacement effect of sedentary behaviour with physical activity on levels of depression while no research exists examining this substitution relationship using objective physical behaviour data. Thus, our findings are novel in

Table 4 Anxiety symptoms: isotemporal substitution analysis of $30 \mathrm{~min} /$ day replacement of physical behaviours

\begin{tabular}{|c|c|c|}
\hline & Crude & Adjusted \\
\hline & Isotemporal & Isotemporal \\
\hline & B (95\% Cl) & B (95\% Cl) \\
\hline $\begin{array}{l}\text { Sedentary } \\
\text { activity }\end{array}$ & Replaced & Replaced \\
\hline $\begin{array}{l}\text { Light } \\
\text { activity }\end{array}$ & $-0.19(-0.42$ to 0.04$)$ & $-0.34(-0.64 \text { to }-0.04)^{*}$ \\
\hline MVPA & $0.10(-0.10$ to 0.31$)$ & $0.08(-0.21$ to 0.36$)$ \\
\hline
\end{tabular}

Models are adjusted for age, gender, season, marital status, smoking status, alcohol consumption, BMI status and education. ${ }^{*} \mathrm{P}<0.05$.

BMI, body mass index; MVPA, moderate-to-vigorous physical activity. 
Table 5 Levels of well-being: isotemporal substitution analysis of $30 \mathrm{~min} /$ day replacement of physical behaviours

\begin{tabular}{|c|c|c|}
\hline & Crude & Adjusted \\
\hline & Isotemporal & Isotemporal \\
\hline & B (95\% Cl) & B (95\% Cl) \\
\hline $\begin{array}{l}\text { Sedentary } \\
\text { activity }\end{array}$ & Replaced & Replaced \\
\hline $\begin{array}{l}\text { Light } \\
\text { activity }\end{array}$ & $0.48(0.02 \text { to } 0.94)^{\star}$ & $0.58(0.05 \text { to } 1.11)^{\star}$ \\
\hline MVPA & $-0.29(-0.70$ to 0.11$)$ & $-0.22(-0.69$ to 0.26$)$ \\
\hline
\end{tabular}

Models are adjusted for age, gender, season, marital status, smoking status, alcohol consumption, BMI status and education. ${ }^{*} \mathrm{P}<0.05$.

$\mathrm{BMI}$, body mass index; MVPA, moderate-to-vigorous physical activity.

this perspective. The lack of consistent findings observed in this study when examining anxiety, well-being and depressive symptoms may suggest that anxiety symptoms and well-being are more sensitive to the effects of physical activity. In addition, the CESD was created for use in the general population. ${ }^{39}$ Our sample was recruited from a primary care centre and thus may be unwell compared with the general population. Thus, the CESD scale may not have been sensitive to depressive symptoms at the lower end of the scale, resulting in inaccurate statistical observations with physical behaviour displacement models. Finally, the demographic characteristics of the samples differed. Mekary et $a l^{14}$ examined the association between subjective physical behaviour and depressive symptom in a large female population of nurses aged 46-71 years, while Loprinzi et $a l^{26}$ examined this association in both men and women in adults aged $\geq 65$ years and older). Overall, women have been found to report lower intensities and levels of activity than men while physical activity levels have been found to decrease with older age. ${ }^{40} 41$ A number of mechanisms of action have been proposed to explain associations between physical activity and mental health. Research has reported acute mental health changes that occur during and following sessions of physical activity, and many long-standing changes are linked to consistent physical activity training. ${ }^{42} 43$ For instance, studies have found physical activity to stimulate changes in mood-related neurotransmitters such as serotonin and endorphins. ${ }^{44-48}$ In addition, positive effects of physical activity on stress and coping strategies have been documented. ${ }^{42} 434950$ Due to the cross-sectional design of this study and research showing the bidirectional relationship between physical activity and mental health outcomes, reverse causality needs to be considered in interpreting study findings. ${ }^{51}$ Furthermore, we cannot exclude the possibility of a third underlying factor that contributes to both mental health and physical activity behaviours. Research by De Moor et $a l^{52}$ found non-causal effects of regular exercise on symptoms of anxiety and depression.

\section{Study strengths and limitations}

The use of a valid and reliable activity monitor which is capable of assessing time spent in sedentary, light, moderate and vigorous activity categories represents a significant strength of this study. ${ }^{31}$ Further strengths include the 24-hour study protocol, the high study participation rate and large sample size. A novel aspect of this study is the use of isotemporal substitution analysis which simultaneously models the specific activity being performed and the specific activity being displaced in an equal time-exchange manner. ${ }^{14}$ The isotemporal substitution model controls for the confounding effect of other activities and also captures the effect of time substitution. Because of these advantages, the interpretation of this model will be more relevant to public health recommendations than models that do not take account of displaced activities.

Some limitations can be identified. Although confounding factors were controlled for, the possibility that unmeasured confounders may also influence the current observations cannot be overlooked. For example, cognitive function was not assessed and it has been suggested that cognitive function is associated with, and mediates, the relationship between physical activity and depression. ${ }^{53}$ Physical activity data were collected over a 1-week period which may not reflect habitual physical activity levels over a longer time period, that is, month or year. A limitation of this study is the cross-sectional nature of the analysis. The cross-sectional associations observed in this study may reflect reverse causal pathways whereby changes in physical behaviour patterns may be the consequence, rather than the cause, of the change in symptoms of anxiety and well-being. Evidence exists that shows the bi-directional relationship between physical activity and mental health outcomes. ${ }^{51}$ It should also be highlighted that the arbitrary cut-point to classify daytime wear may lead to inaccurate estimates of sedentary activity. For example, persons who sleep later than 6 am will have inflated sedentary behaviour estimates while those who are active before 6 am or after 12-midnight will have deflated activity estimates. Generalisability of these findings may also be limited. The Mitchelstown cohort was a random sample of middle-aged adults, 50-69 years of age, in an area which was representative of both urban and rural population in Ireland. The subsample for whom accelerometer data were collected differed somewhat by gender, as women were more likely to agree to wear the accelerometer. However, it should be noted that there were no statistically significant differences in age, gender, education or BMI between those included and excluded in the final analysis. In addition, participants were recruited from a primary care centre, and therefore could have more health problems or be more health conscious.

\section{CONCLUSION}

Our findings suggest that replacing short daily periods of sedentary behaviour with light activity may be associated with reduced anxiety symptoms and greater well-being among middle-aged adults. Prospective and experimental 
studies are needed to further elucidate the mental health benefits of replacing sedentary behaviour with other activities.

Acknowledgements The authors would like to acknowledge HRB Ireland for funding this research.

Contributors CBD, EMM and IJP: contributed to the conception and design of the study. CBD: collected and analysed the accelerometry data; conducted the statistical analyses; drafted and revised the manuscript. CBD, EMM, GO'R and IJP: interpreted the results. EMM, GO'R and IJP: gave critical input on the manuscript. All authors: read and approved the final version of the manuscript.

Funding This work was supported by a research grant from the Irish Health Research Board (reference HRC/2007/13).

Competing interests None declared.

Patient consent Obtained.

Ethics approval The study was approved by the Clinical Research Ethics Committee of University College Cork. Written informed consent to participate was obtained from all participants.

Provenance and peer review Not commissioned; externally peer reviewed.

Data sharing statement Extra data are available by emailing c.dillon@ucc.ie.

Open Access This is an Open Access article distributed in accordance with the Creative Commons Attribution Non Commercial (CC BY-NC 4.0) license, which permits others to distribute, remix, adapt, build upon this work non-commercially, and license their derivative works on different terms, provided the original work is properly cited and the use is non-commercial. See: http://creativecommons.org/ licenses/by-nc/4.0/

(c) Article author(s) (or their employer(s) unless otherwise stated in the text of the article) 2018. All rights reserved. No commercial use is permitted unless otherwise expressly granted.

\section{REFERENCES}

1 World Health Organisation. Investing in treatment for depression and anxiety leads to fourfold return. Secondary Investing in treatment for depression and anxiety leads to fourfold return, 2016.

2 Fiske A, Wetherell JL, Gatz M. Depression in older adults. Annu Rev Clin Psychol 2009:5:363-89.

3 Martinsen EW. Physical activity in the prevention and treatment of anxiety and depression. Nord J Psychiatry 2008;62:25-9.

4 Dinas PC, Koutedakis Y, Flouris AD. Effects of exercise and physical activity on depression. Ir J Med Sci 2011;180:319-25.

5 Teychenne M, Ball K, Salmon J. Physical activity and likelihood of depression in adults: a review. Prev Med 2008;46:397-411.

6 Ströhle A. Physical activity, exercise, depression and anxiety disorders. J Neural Transm 2009;116:777-84.

7 Kim YS, Park YS, Allegrante JP, et al. Relationship between physical activity and general mental health. Prev Med 2012;55:458-63.

8 Shen D, Mao W, Liu T, et al. Sedentary behavior and incident cancer: a meta-analysis of prospective studies. PLoS One 2014;9:e105709.

9 Cooper AJ, Brage S, Ekelund U, et al. Association between objectively assessed sedentary time and physical activity with metabolic risk factors among people with recently diagnosed type 2 diabetes. Diabetologia 2014;57:73-82.

10 Ekblom Ö, Ekblom-Bak E, Rosengren A, et al. Cardiorespiratory fitness, sedentary behaviour and physical activity are independently associated with the metabolic syndrome, results from the SCAPIS pilot study. PLoS One 2015;10.

11 Salonen MK, Wasenius N, Kajantie E, et al. Physical activity, body composition and metabolic syndrome in young adults. PLoS One 2015;10:e0126737

$12 \mathrm{Hu} \mathrm{B}$, Liu X, Wang C, et al. Vigorous-intensity physical activity is associated with metabolic syndrome among the Chinese middleaged population: a cross-sectional study. Int J Sport Nutr Exerc Metab 2015;25:119-27.

13 Rebar AL, Stanton R, Geard D, et al. A meta-meta-analysis of the effect of physical activity on depression and anxiety in non-clinical adult populations. Health Psychol Rev 2015;9:366-78.

14 Mekary RA, Lucas M, Pan A, et al. Isotemporal substitution analysis for physical activity, television watching, and risk of depression. Am J Epidemiol 2013;178:474-83.
15 Mekary RA, Willett WC, Hu FB, et al. Isotemporal substitution paradigm for physical activity epidemiology and weight change. Am $J$ Epidemiol 2009;170:519-27.

16 Bonnefoy M, Normand S, Pachiaudi C, et al. Simultaneous validation of ten physical activity questionnaires in older men: a doubly labeled water study. J Am Geriatr Soc 2001;49:28-35.

17 Sallis JF, Saelens BE. Assessment of physical activity by selfreport: status, limitations, and future directions. Res $Q$ Exerc Sport 2000;71:1-14.

18 Adams SA, Matthews CE, Ebbeling CB, et al. The effect of social desirability and social approval on self-reports of physical activity. Am J Epidemiol 2005;161:389-98.

19 Carson V, Ridgers ND, Howard BJ, et al. Light-intensity physical activity and cardiometabolic biomarkers in US adolescents. PLOS One 2013;8:e71417.

20 Tudor-Locke CE, Myers AM. Challenges and opportunities for measuring physical activity in sedentary adults. Sports Med 2001;31:91-100.

21 Manson JE, Hu FB, Rich-Edwards JW, et al. A prospective study of walking as compared with vigorous exercise in the prevention of coronary heart disease in women. N Engl J Med 1999;341:650-8.

22 Wai JP, Wen CP, Chan HT, et al. Assessing physical activity in an Asian country: low energy expenditure and exercise frequency among adults in Taiwan. Asia Pac J Clin Nutr 2008;17:297-308.

23 Pate RR, Pratt M, Blair SN, et al. Physical activity and public health. A recommendation from the centers for disease control and prevention and the American college of sports medicine. JAMA 1995;273:402-7.

24 Chastin SF, Dall PM, Tigbe WW, et al. Compliance with physical activity guidelines in a group of UK-based postal workers using an objective monitoring technique. Eur J Appl Physiol 2009;106:893-9.

25 Collins LL ST. L. Latent class and latent transition analysis with application in the social, behavioral, and health sciences. Hoboken, New Jersey: John Wiley \& Sons, 2010.

26 Loprinzi PD. Objectively measured light and moderate-to-vigorous physical activity is associated with lower depression levels among older US adults. Aging Ment Health 2013;17:801-5.

27 Healy GN, Winkler EA, Brakenridge CL, et al. Accelerometer-derived sedentary and physical activity time in overweight/obese adults with type 2 diabetes: cross-sectional associations with cardiometabolic biomarkers. PLoS One 2015;10:e0119140.

28 Hamer M, Stamatakis E, Steptoe A. Effects of substituting sedentary time with physical activity on metabolic risk. Med Sci Sports Exerc 2014;46:1946-50.

29 Epstein LH, Roemmich JN, Paluch RA, et al. Physical activity as a substitute for sedentary behavior in youth. Ann Behav Med 2005;29:200-9

30 Kearney PM, Harrington JM, Mc Carthy VJ, et al. Cohort profile: the cork and kerry diabetes and heart disease study. Int $J$ Epidemiol 2013;42:1253-62.

31 Esliger DW, Rowlands AV, Hurst TL, et al. Validation of the GENEA accelerometer. Med Sci Sports Exerc 2011;43:1085-93.

32 Dillon CB, Fitzgerald AP, Kearney PM, et al. Number of days required to estimate habitual activity using Wrist-Worn GENEActiv accelerometer: a cross-sectional study. PLoS One 2016;11:e0109913.

33 van Hees VT, Renström F, Wright A, et al. Estimation of daily energy expenditure in pregnant and non-pregnant women using a wristworn tri-axial accelerometer. PLoS One 2011;6:e22922.

34 Radloff L. The CES-D Scale: a self-report depression scale for research in the general population. Appl Psychol Meas 1977;1:385-401.

35 Zigmond AS, Snaith RP. The hospital anxiety and depression scale. Acta Psychiatr Scand 1983;67:361-70.

36 Bech P. Quality of life in the psychiatric patient. London: MosbyWolfe, 1998.

37 Bech P. Clinical psychometrics. Oxford: Wiley-Balckwell, 2012.

38 Hamer M, Stamatakis E. Prospective study of sedentary behavior, risk of depression, and cognitive impairment. Med Sci Sports Exerc 2014;46:718-23.

39 Radloff LS. The CES-D Scale: a self-report depression scale for research in the general population. Appl Psychol Meas 1977;1:385-401.

40 Ransdell LB, Vener JM, Sell K. International perspectives: the influence of gender on lifetime physical activity participation. J $R$ Soc Promot Health 2004;124:12-14.

41 Morgan K, McGee H, Watson D, et al. SLAN 2007: survey of lifestyle, attitudes \& nutrition in Ireland: main report. Psychol Rep 2008;3.

42 Read JP, Brown RA. The role of physical exercise in alcoholism treatment and recovery. Prof Psychol 2003;34:49-56. 
43 Stathopoulou G, Powers MB, Berry AC, et al. Exercise interventions for mental health: a quantitative and qualitative review. Clin Psychol Sci Pract 2006;13:179-93.

$44 \mathrm{Ng} \mathrm{F}$, Dodd S, Berk M. The effects of physical activity in the acute treatment of bipolar disorder: a pilot study. J Affect Disord 2007;101:259-62.

$45 \mathrm{Ng} \mathrm{F}$, Dodd S, Jacka FN, et al. Effects of a walking program in the psychiatric in-patient treatment setting: a cohort study. Health Promot J Austr 2007;18:39-42.

46 Chaouloff F. Effects of acute physical exercise on central serotonergic systems. Med Sci Sports Exerc 1997;29:58-62.

47 Fumoto M, Oshima T, Kamiya K, et al. Ventral prefrontal cortex and serotonergic system activation during pedaling exercise induces negative mood improvement and increased alpha band in EEG. Behav Brain Res 2010;213:1-9.

48 Meeusen R, Piacentini MF, De Meirleir K. Brain microdialysis in exercise research. Sports Med 2001;31:965-83.
49 Rejeski WJ, Thompson A, Brubaker PH, et al. Acute exercise: buffering psychosocial stress responses in women. Health Psychol 1992;11:355-62.

50 Rimmele U, Zellweger BC, Marti B, et al. Trained men show lower cortisol, heart rate and psychological responses to psychosocial stress compared with untrained men. Psychoneuroendocrinology 2007;32:627-35.

51 Azevedo Da Silva M, Singh-Manoux A, Brunner EJ, et al. Bidirectional association between physical activity and symptoms of anxiety and depression: the Whitehall II study. Eur J Epidemiol 2012;27:537-46.

52 De Moor MH, Boomsma DI, Stubbe JH, et al. Testing causality in the association between regular exercise and symptoms of anxiety and depression. Arch Gen Psychiatry 2008;65:897-905.

53 Birch K, Ten Hope M, Malek-Ahmadi M, et al. Cognitive function as a mediator in the relationship between physical activity and depression status in older adults. J Aging Phys Act 2016;24:540-6. 